\title{
Polysaccharide purified from Lycium barbarum protects differentiated PC12 cells against L-Glu-induced toxicity via the mitochondria-associated pathway
}

\author{
LING KOU ${ }^{1}$, MINGZHAO DU ${ }^{1}$, CHAOPU ZHANG $^{1}$, ZHIYIN DAI $^{1}, \mathrm{XUAN} \mathrm{LI}^{1}$, BAOHAI ZHANG $^{1}$ and XINYU HU ${ }^{2}$ \\ ${ }^{1}$ Department of Vasculocardiology, Affiliated Hospital of Jiangsu University, Jiangsu University, Zhenjiang, \\ Jiangsu 212001; ${ }^{2}$ Faculty of Medicine, Changchun Medical College, Changchun, Jilin 130013, P.R. China
}

Received September 15, 2016; Accepted June 13, 2017

DOI: $10.3892 / \mathrm{mmr} .2017 .7289$

\begin{abstract}
The present study successfully demonstrated the neuroprotective effects of purified Lycium barbarum polysaccharide (LBPS02) against glutamate (L-Glu)-induced differentiated PC12 (DPC12) cell apoptosis. Purified polysaccharide was obtained by using a diethylaminoethyl-52 cellulose anion exchange column and a Sepharose G-100 column. During identification and characterization, LBPS02 was validated to be a fraction with $68 \mathrm{kDa}$ molecular weight, and with a structure containing $1 \rightarrow 3,1 \rightarrow 4$ and $1 \rightarrow 6$ linkages. Data further revealed that LBPS02 pretreatment effectively improved cell viability, reduced apoptosis rate, and restored the mitochondrial dysfunction in L-Glu-exposed cells. LBPS02 suppressed L-Glu-induced reactive oxygen species (ROS accumulation in DPC12 cells. N-acetylcysteine, a ROS inhibitor, strongly enhanced the efficacy of LBPS02. Furthermore, LBPS02 normalized the levels of anti-apoptotic proteins, and regulated the phosphorylation of extracellular signal-regulated kinases (ERKs) and protein kinase B (Akt) in L-Glu-explored DPC12 cells. In conclusion, LBPS02-mediated neuroprotective effects are at least partially associated with the modulation of Akt and ERKs, and the subsequent inhibition of the mitochondrial apoptotic pathway. LBPS02 may be a candidate for neurodegenerative disease treatment.
\end{abstract}

\section{Introduction}

Neurodegenerative disorders have received research attention due to their devastating nature and unsuccessful therapies. Although the etiology of these diseases remains unknown, oxidative damage, mitochondrial dysfunction and protein

Correspondence to: Dr Mingzhao Du, Department of Vasculocardiology, Affiliated Hospital of Jiangsu University, Jiangsu University, 438 Jiefang Road, Zhenjiang, Jiangsu 212001, P.R. China E-mail:dumz@ujs.edu.cn

Key words: Lycium barbarum, polysaccharides, neuroprotection, glutamate, mitochondria aggregation are reported as common pathological features of neurological disorders $(1,2)$. In the brain, glutamate (L-Glu) acts as a fast excitatory neurotransmitter in the central nervous system, and is responsible for two major intracellular toxicity pathways $(3,4)$. Excessive accumulation of L-Glu leads to the collapse of mitochondrial membrane potential (MMP), which is initiated by B-cell lymphoma 2 (Bcl-2) family members including the pro- and anti-apoptotic proteins. As reported previously, L-Glu-induced cell apoptosis is associated with the activation of extracellular signal-regulated kinases (ERKs) and protein kinase $\mathrm{B}$ (Akt) (5). Akt is involved in regulating oxidative stress in neuronal cells, and ERKs participates in mitochondria-mediated apoptotic cell death (6).

Herbal medicines, including Ginseng radix and Polygalae radix, are reported to exhibit broad protective properties in various neurodegenerative diseases $(7,8)$. Currently, the acquisition of bioactive ingredient from herbs has become an important study focus. Purified polysaccharides from the flowers of Nerium indicum exhibit protective activities against $\beta$-amyloid (A $\beta$ ) peptides in cortical neurons (8). A 75-kDa polysaccharides purified from Sparassis crispa has neuroprotective effects against L-Glu-induced cell damage via the mitochondria-associated apoptotic pathway (9). Based on previous conclusions, the chemical composition, glycosidic linkages and degree of branching are responsible for the bioactivities of polysaccharides (10).

As a medicinal plant, Lycium barbarum has been widely used in southeast Asia. The immunoregulatory, neuroprotective and antifatigue effects of $L$. barbarum have been widely reported by previous studies (11-13). L. barbarum polysaccharide (LBPS) prevents 6-hydroxydopamine-induced PC12 cell apoptosis partially via effects on the reactive oxygen species (ROS)-nitric oxide (NO) pathway (14). L. barbarum polysaccharides prevent damage to retinal ganglion cells from acute ocular hypertension-induced ischemic injury (15). These encouraging data prompted further investigation of the neuroprotective effects of purified polysaccharides from L. barbarum and the potential underlying mechanisms.

In the present study, functional polysaccharides of L. barbarum were purified and characterized. In L-Glu-induced apoptotic differentiated rat pheochromocytoma (DPC12) cells, the protective effects of the purified polysaccharides 
were investigated. Cell viability, apoptotic rate, mitochondrial function and the expression of associated proteins were detected to determine whether purified polysaccharides from L. barbarum were neuroprotective against L-Glu-induced toxicity in DPC12 cells.

\section{Materials and methods}

Polysaccharide purification and characterization. Purification of L. barbarum polysaccharides. L. barbarum (obtained from Ningxia province, China) was extracted with water $(100 \mathrm{~g} \mathrm{~L}$. barbarum in $500 \mathrm{ml})$ twice at $80^{\circ} \mathrm{C}$ for $3 \mathrm{~h}$. The collected supernatant was concentrated at $37^{\circ} \mathrm{C}$ and $4,000 \mathrm{x} \mathrm{g}$ for $10 \mathrm{~min}$ and proteins were removed using $50 \mathrm{ml}$ Sevag reagent (n-butanol: chloroform, 1:4 vol). The polysaccharides were purified according to previous methods (16). Following precipitation with 4 -fold ethanol at $4^{\circ} \mathrm{C}$ for $12 \mathrm{~h}$, the precipitate was dissolved in double distilled water and subjected to a diethylaminoethyl (DEAE)-52 cellulose anion exchange column $(2.6 \mathrm{~cm}$ x $35 \mathrm{~cm}$; Whatman; GE Healthcare Life Sciences, Little Chalfont, UK) and a gel permeation chromatography system (Sepharose G-100; Pharmacia; GE Healthcare Life Sciences). The fraction was collected, detected, freeze-dried and designated LBPSO2 (Fig. 1A).

Molecular weight measurement. The methodology was similar to previous studies (9). LC-10ATvp high-performance liquid chromatography (HPLC) system (Shimadzu Corporation, Kyoto, Japan) equipped with a TSK-GEL G4000PWXL column (Tosoh Corporation, Tokyo, Japan) and an Alltech 2000ES evaporative light scattering detector (ELSD; Shimadzu Corporation) was used to analyze the molecular weight of purified polysaccharides $(10 \mu \mathrm{l})$. D.D. water was used as the mobile phase with $0.45 \mathrm{ml} / \mathrm{min}$ flow rate, $60 \%$ aerosol level, $120^{\circ} \mathrm{C}$ drift tube temperature and 25 psi nebulizing nitrogen pressure. Dextran standards (31430; Sigma-Aldrich; Merck KGaA, Darmstadt, Germany) were used to create a calibration curve.

Ultraviolet $(U V)$ spectra and Fourier transform infrared spectroscopy (FTIR) measurement. The UV spectra of LBPS02 were detected by UV-2401 PC UV-Vis recording spectrophotometer (Shimadzu Corporation) scanning from 200-400 nm. The scanning was repeated 5 times. The transmission spectra of LBPS02 were recorded via an IRPrestige-21 FTIR spectrometer (Shimadzu Corporation) at wavelength ranging from $900-4,000 \mathrm{~cm}^{-1}$.

Monosaccharides analysis. Similar to previous studies (9), $20 \mathrm{mg}$ LBPS02 was hydrolyzed with $1 \mathrm{M} \mathrm{H}_{2} \mathrm{SO}_{4}(1 \mathrm{ml})$ at $105^{\circ} \mathrm{C}$ for $6 \mathrm{~h}$ in a sealed glass tube. Following $\sim \mathrm{pH}$ adjustment to 7.0 and centrifugation at $4,000 \mathrm{x}$ g for $10 \mathrm{~min}$, the hydrolysates were analyzed using the HPLC/ELSD system. D-glucose, D-galactose, D-mannose, D-xylose, L-rhamnose and L-arabinose were used as monosaccharide standards (Sigma-Aldrich; Merck KGaA).

Periodate oxidation-Smith degradation reaction of LBPSO2. Similar to previous studies (17), $20 \mathrm{mg}$ of LBPS02 was dissolved in $15 \mathrm{mM} \mathrm{NaIO}_{4}(25 \mathrm{ml} ; \mathrm{pH} 4)$ at $4^{\circ} \mathrm{C}$ in darkness.
$\mathrm{NaIO}_{4}$ in various concentrations was used to create a calibration curve to calculate the $\mathrm{HIO}_{4}$ consumption, while the formic acid production was determined by titration. D.D. water served as control. After $48 \mathrm{~h}$ of dialyzing, the concentrated dialysate was incubated with $70 \mathrm{mg}$ potassium borohydride overnight at room temperature. Following $\mathrm{pH}$ adjustment to 7.0 and another $24 \mathrm{~h}$ of dialyzing, one part of the sample was detected by HPLC/ELSD system. Another part of the sample was hydrolyzed with $1 \mathrm{M} \mathrm{H}_{2} \mathrm{SO}_{4}$ at $25^{\circ} \mathrm{C}$ for $40 \mathrm{~h}$, and the hydrolysates were analyzed by HPLC/ELSD.

Cell culture. Rat adrenal gland pheochromocytoma PC12 cells (American Type Culture Collection, Manassas, VA, USA; CRL-1721; passage <10) were cultured in Dulbecco's modified Eagle medium (DMEM) supplemented with 5\% horse serum (HS), $10 \%$ fetal bovine serum (FBS), penicillin (100 U/ml), and streptomycin $(100 \mu \mathrm{g} / \mathrm{ml})$, under a humidified atmosphere containing $95 \%$ air and $5 \% \mathrm{CO}_{2}$ at $37^{\circ} \mathrm{C}$. Nerve growth factor (NGF; $50 \mathrm{ng} / \mathrm{ml}$ ) was used to differentiate PC12 cells for $48 \mathrm{~h}$ in DMEM medium containing $1 \%$ FBS and $1 \%$ HS. All agents were obtained from Invitrogen (Thermo Fisher Scientific, Inc., Waltham, MA, USA).

Cell viability analysis. DPC12 cells $\left(2 \times 10^{4}\right.$ cells) were seeded into 96-well plates, then treated with LBPS02 at doses of 10 and $30 \mu \mathrm{g} / \mathrm{ml}$ alone for $24 \mathrm{~h}$, or pretreated with LBPS02 for $3 \mathrm{~h}$ prior to incubation with $20 \mathrm{mM} \mathrm{L}$-Glu for another $24 \mathrm{~h}$. In a separate experiment, cells were exposed to $1 \mathrm{mM}$ of N-Acetyl-L-cysteine (NAC; S0077; Beyotime Institute of Biotechnology, Haimen, China) a ROS inhibitor for $30 \mathrm{~min}$, followed by a $3-\mathrm{h}$ incubation with $30 \mu \mathrm{g} / \mathrm{ml} \mathrm{LBPS} 02$, and then treated with $20 \mathrm{mM} \mathrm{L}$-Glu for another $24 \mathrm{~h}$. Treated cells were then incubated with $0.5 \mathrm{mg} / \mathrm{ml} 3$-(4,5-cimethylthiazol-2-yl)-2,5-diphenyl tetrazolium bromide (MTT; Sigma-Aldrich; Merck KGaA) for $4 \mathrm{~h}$ at $37^{\circ} \mathrm{C}$ in darkness. Following addition of dimethyl sulfoxide (DMSO; $100 \mu \mathrm{l}$ ), a microplate reader (Bio-Rad Laboratories, Inc., Hercules, CA, USA) was used to measure the absorbance at a wavelength of $540 \mathrm{~nm}$.

Cell apoptosis analysis. DPC12 cells $\left(1 \times 10^{5}\right)$ were pretreated with 10 and $30 \mu \mathrm{g} / \mathrm{ml}$ for $3 \mathrm{~h}$, and then co-incubated with $20 \mathrm{mM}$ L-Glu for another $24 \mathrm{~h}$. Cells were harvested and incubated with $5 \mu$ l Annexin V-fluorescein isothiocyanate $(20 \mu \mathrm{g} / \mathrm{ml})$ and $5 \mu \mathrm{l}$ propidium iodide (PI; $50 \mu \mathrm{g} / \mathrm{ml}$; BD Biosciences, Franklin Lakes, NJ, USA) for 20 min in darkness at room temperature. Cell apoptosis was analyzed using flow cytometry (FC500; Beckman Coulter, Inc., Brea, CA, USA).

Measurement of ROS concentration and caspase-3 activition. DPC12 cells $\left(1 \times 10^{5}\right)$ were pretreated with 10 and $30 \mu \mathrm{g} / \mathrm{ml}$ LBPS02 for $3 \mathrm{~h}$, and then co-incubated with $20 \mathrm{mM} \mathrm{L}$-Glu for $24 \mathrm{~h}$. Treated cells were harvested and lysed using radioimmunoprecipitation assay (RIPA) buffer (Sigma-Aldrich; Merck $\mathrm{KGaA}$ ). Following detection of protein concentration using BCA Protein Assay kit, the intracellular ROS levels (Reactive oxygen species Assay kit) and caspase-3 activation (Caspase-3 activity assay kit) were determined according to protocols of commercial kits purchased from Nanjing Jiancheng Bioengineering Institute (Nanjing, China). 
A

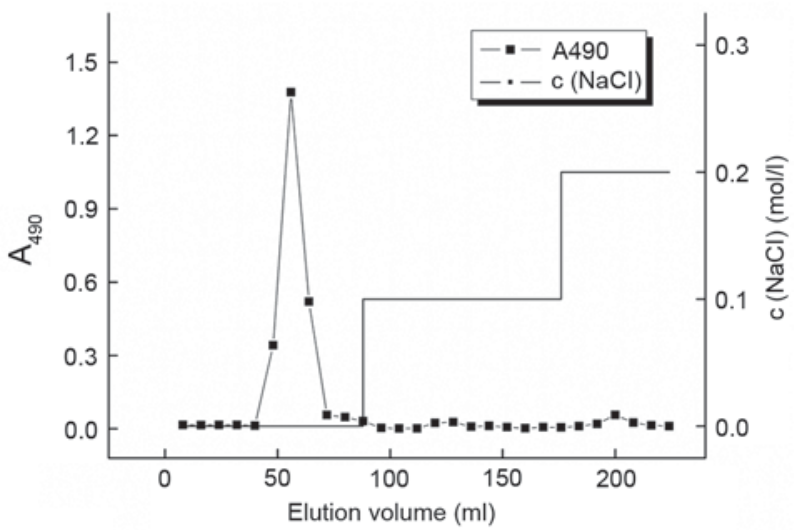

C





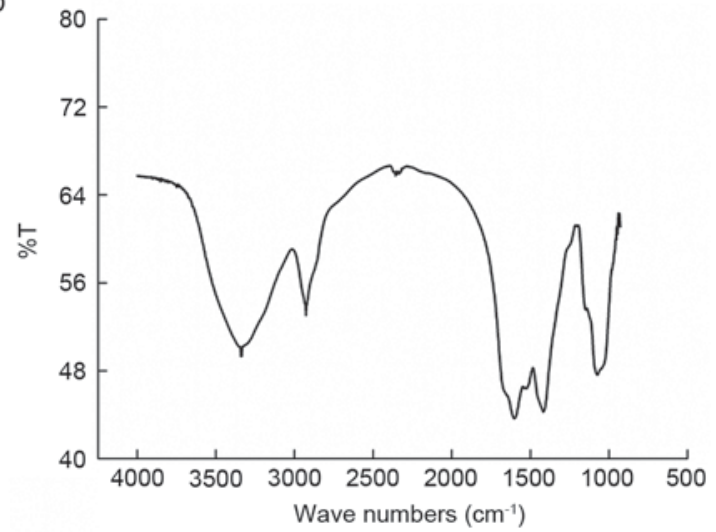

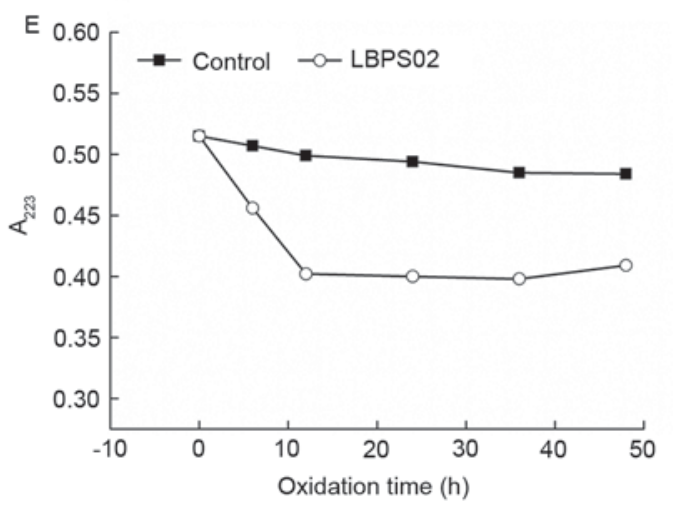

Smith degradation products

\begin{tabular}{lllll}
\hline Constituents & $\begin{array}{l}\text { L-rhamnose } \\
\text { monohydrate }\end{array}$ Mannose & Glucose Glycerol Erythritol \\
\hline
\end{tabular}

Before hydrolysis

Outside

Inside

"+" Detected; “"” undetected

Figure 1. Purification and characterization of LBPS02. (A) DEAE-52 cellulose anion exchange chromatogram of the crude polysaccharides. Polysaccharides were eluted by double-distilled water and $0.1 \mathrm{~mol} / 1 \mathrm{NaCl}$. (B) Crude polysaccharides were purified by Sepharose G-100. (C) Ultraviolet spectrum of LBPS02 . (D) Fourier transform infrared spectroscopy spectrum of LBPS02. (E) Periodate oxidation time course with control (D.D. water). (F) Products of hydrolysates of LBPS02 following Smith degradation analysis via high-performance liquid chromatography. $\mathrm{A}_{490}$, absorbance at $490 \mathrm{~nm}$; $\mathrm{A}_{223}$, absorbance at $223 \mathrm{~nm}$; LPBS, Lycium barbarum polysaccharide.

The intracellular ROS levels were also determined by flow cytometry. Treated cells were harvested and incubated with $10 \mu \mathrm{M}$ dichloro-dihydro-fluorescein diacetate at $37^{\circ} \mathrm{C}$ for $10 \mathrm{~min}$ in darkness. After three washes with phosphate-buffered saline, the changes of intracellular ROS level were analyzed by flow cytometry (FC500; Beckman Coulter, Inc.).

Measurement of MMP. DPC12 cells $\left(2 \times 10^{5}\right)$ were pretreated 10 and $30 \mu \mathrm{g} / \mathrm{ml}$ with LBPS02 for $3 \mathrm{~h}$ and then co-incubated with $20 \mathrm{mM} \mathrm{L}$-Glu for another $24 \mathrm{~h}$. Cells were incubated with $2 \mu \mathrm{M}$ 5,5',6,6'-tetrachloro-1,1',3,3' etraethylbenzimidazolylcarbocyanine iodide (Sigma-Aldrich; Merck KGaA) at $37^{\circ} \mathrm{C}$ for $10 \mathrm{~min}$. The fluorescence intensity was detected via Nikon Eclipse TE 2000-S fluorescent microscope (x20; charge coupled device camera; Nikon Corporation, Tokyo, Japan). The fluorescence intensity was quantified by ImageJ version 1.38x (National Institutes of Health, Bethesda, MD, USA).

Western blot analysis. DPC12 cells $\left(1 \times 10^{5}\right)$ were pretreated with 10 and $30 \mu \mathrm{g} / \mathrm{ml}$ LBPSO2 for $3 \mathrm{~h}$, and then co-incubated with $20 \mathrm{mM} \mathrm{L}$-Glu for another $24 \mathrm{~h}$. In another experiment, DPC1 2 cells were treated with 10 and $30 \mu \mathrm{g} / \mathrm{ml} \mathrm{LBPS02}$ alone, $20 \mathrm{mM}$ L-Glu alone or pretreated with 10 and $30 \mu \mathrm{g} / \mathrm{ml}$ LBPS02 for $3 \mathrm{~h}$, and then co-exposed to L-Glu. After incubation for 30-240 min, cells were harvested and lysed by RIPA buffer contained with $1 \%$ protease inhibitor cocktail (Sigma-Aldrich; Merck KGaA). Following detection of protein 



FITC

E

FITC
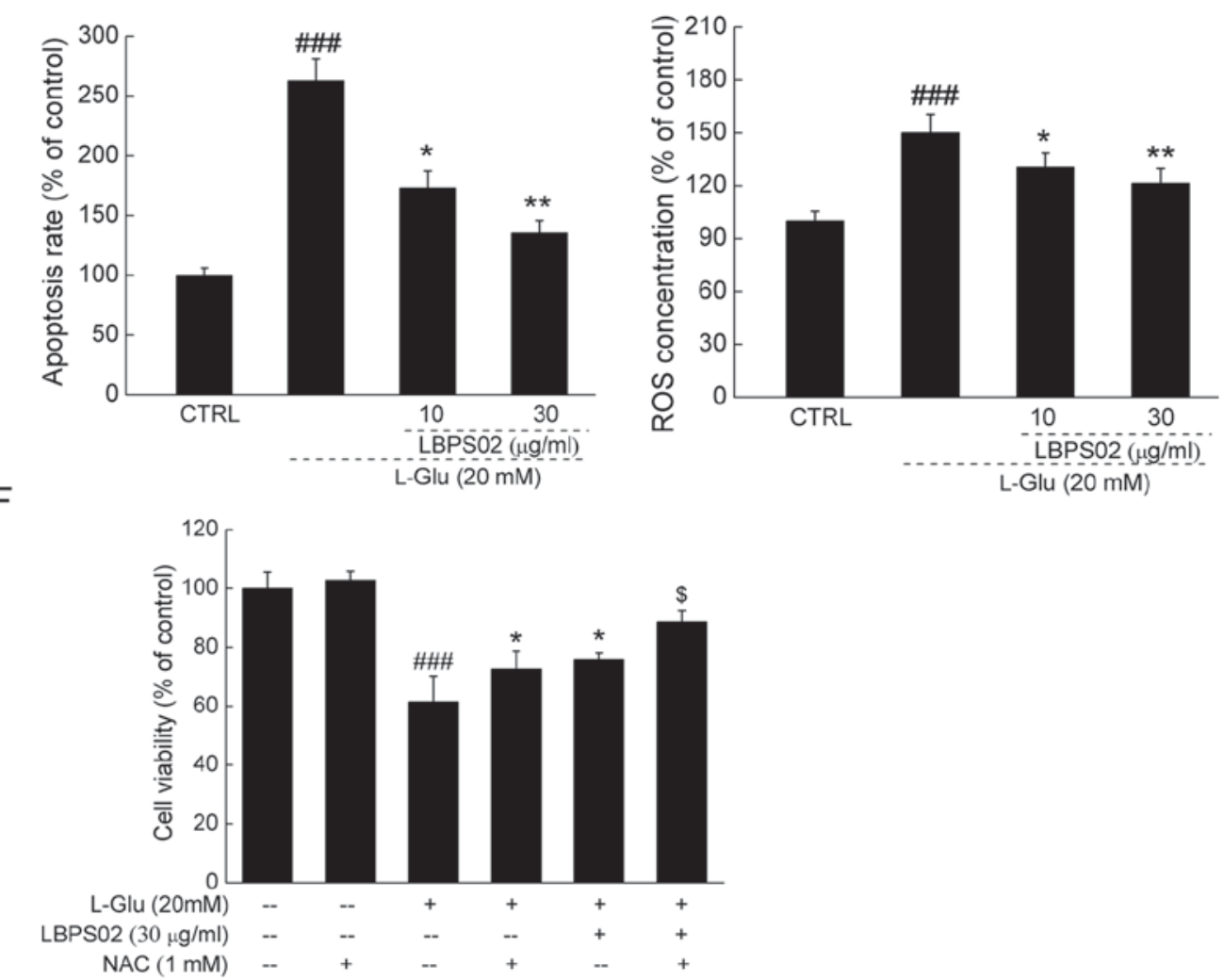

Figure 2. LBPS02 exhibits protective effects against L-Glu-induced DPC12 cells damage. Cells were pretreated with LBPS02 for $3 \mathrm{~h}$, and then exposed to $20 \mathrm{mM} \mathrm{L-Glu}$ for $24 \mathrm{~h}$. (A) Cell viability $(\mathrm{n}=6)$, (B) casapase-3 activation $(\mathrm{n}=6)$ and $(\mathrm{C})$ cell apoptosis rate $(\mathrm{n}=6)$ were detected. Intracellular ROS accumulation were measured and compared with L-Glu-treated cells by (D) flow cytometry $(n=6)$ and (E) using a ROS detection kit $(n=6)$. (F) Cells were also treated with $1 \mathrm{mM}$ NAC and cell viability was measured $(\mathrm{n}=6)$. ${ }^{\# \#} \mathrm{P}<0.01$ and ${ }^{\# \# \#} \mathrm{P}<0.001$ vs. control cells; ${ }^{*} \mathrm{P}<0.05$ and ${ }^{* *} \mathrm{P}<0.01$ vs. L-Glu-exposed cells; ${ }^{\text {S }} \mathrm{P}<0.05$ vs. LBPS02-treated cells. CTRL, control; LPBS, Lycium barbarum polysaccharide; L-Glu, L-glutamine; PI propidium iodide; FITC, fluorescein isothiocyanate; ROS, reactive oxygen species; NAC, $\mathrm{N}$-acetylcysteine. 

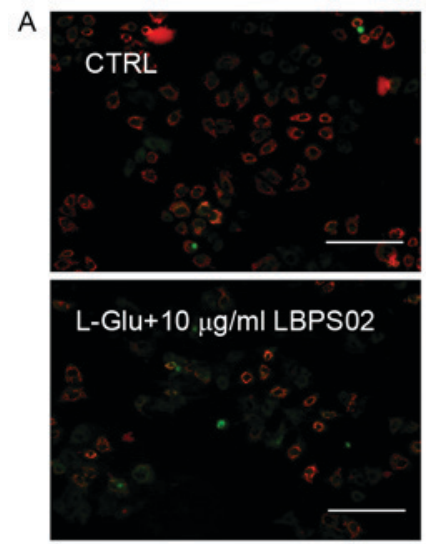

B
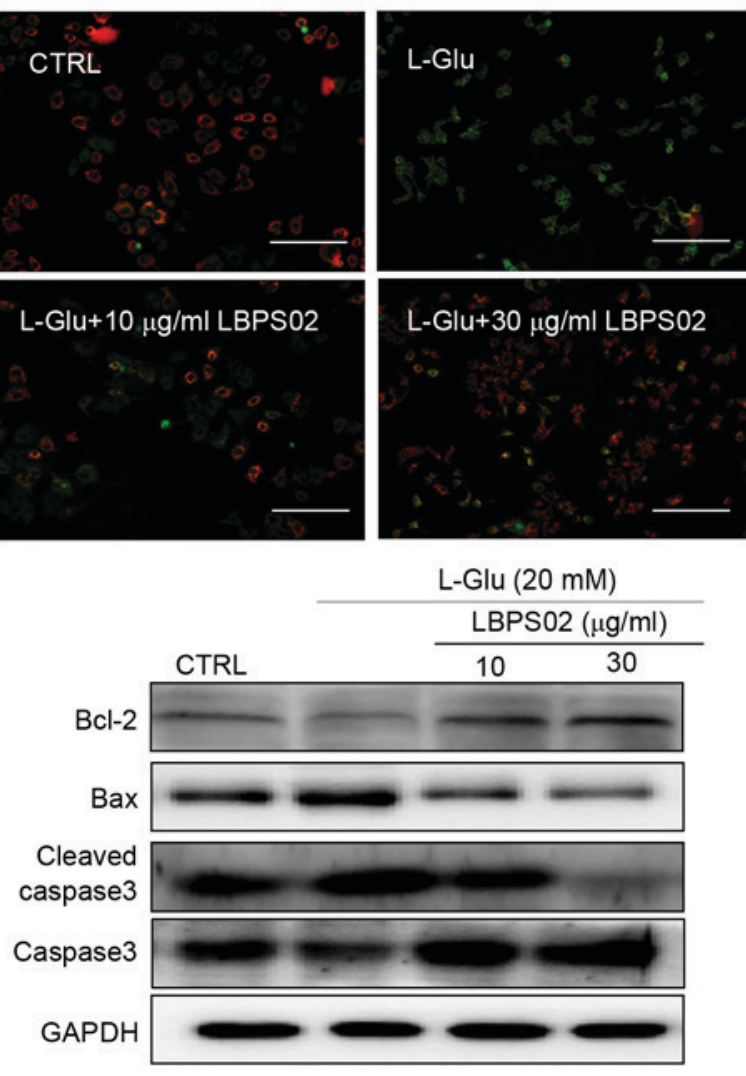
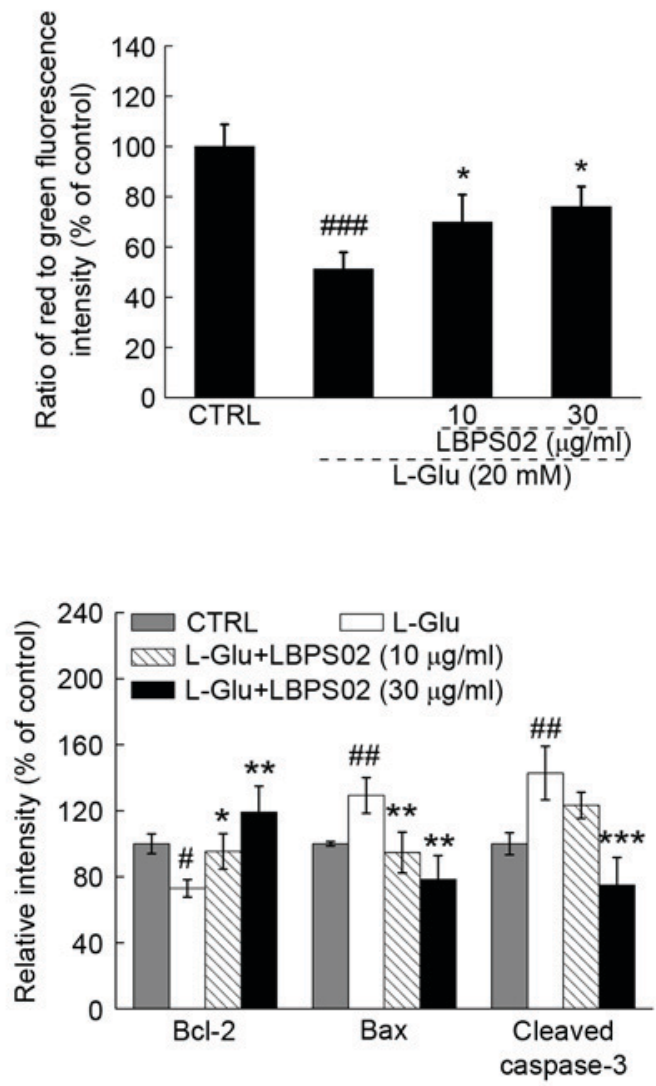

Figure 3. LBPS02 improves mitochondrial function in L-Glu-exposed DPC12 cells. Cells were pretreated with LBPS02 for 3 h, and then exposed to 20 mM L-Glu for 24 h. (A) MMP loss was measured using JC-1 (magnification, x20; scale bar, $100 \mu \mathrm{m}$; $\mathrm{n}=6$ ). (B) Bcl-2, Bax and cleaved caspase-3 were detected in L-Glu-exposed DPC12 cells. Quantification data were normalized to GAPDH. Data re expressed as a percentage of corresponding control cells and the mean \pm standard deviation $(\mathrm{n}=3) .{ }^{\#} \mathrm{P}<0.05,{ }^{\# \#} \mathrm{P}<0.01$ and ${ }^{\# \# \#} \mathrm{P}<0.001$ vs. control cells; ${ }^{*} \mathrm{P}<0.05,{ }^{* *} \mathrm{P}<0.01$ and ${ }^{* * *} \mathrm{P}<0.001$ vs. L-Glu-exposed cells. CTRL, control; L-Glu, L-glutamine; LPBS, Lycium barbarum polysaccharide; Bcl-2, B-cell lymphoma 2; Bax, Bcl-2 associated X apoptosis regulator.

concentration via the Coomassie Brilliant Blue method, $30 \mu \mathrm{g}$ proteins were separated by $10-12 \%$ SDS-PAGE and transferred electrophoretically onto nitrocellulose membranes $(0.22 \mu \mathrm{m}$; Bio Basic, Inc., Markham, ON, Canada). The transferred membranes were blocked in $5 \%$ bull serum albumin (BSA) at room temperature for $4 \mathrm{~h}$, and then the membranes were incubated with the following primary antibodies at 1:1,000 dilution overnight at $4^{\circ} \mathrm{C}$ : total (t)-Akt (ab108266), phosphor (p)-Akt (ab18206), t-ERKs (ab36991), p-ERKs (ab201015), Bcl-2 (ab321224), Bcl-2 associated X apoptosis regulator (Bax) (ab32503), cleaved caspase-3 (ab49822), caspase-3 (ab13847) and GAPDH (ab8245; all Abcam, Cambridge, UK), followed by incubation with horseradish peroxidase-conjugated secondary antibodies (SC2005; Santa Cruz Biotechnology, Inc., Dallas, TX, USA) using 2\% BSA at dilution of 1:2,000 at $4^{\circ} \mathrm{C}$ for $4 \mathrm{~h}$. Enhanced chemiluminescence detection kits (GE Healthcare Life Sciences, Little Chalfont, UK) were applied for chemiluminescence, and the band intensity was quantified by scanning densitometry via Image J version 1.38x (National Institutes of Health).

Statistical analysis. Data are expressed as mean \pm standard deviation, and evaluated by a one-way analysis of variance followed by Dunn's test using SPSS software version 16.0 (SPSS, Inc., Chicago, IL, USA). P<0.05 was considered to indictae a statistically significant difference.

\section{Results}

Purification and characterization of LBPSO2. Following purification by a DEAE-cellulose column and a Sepharose G-100 gel permeation chromatography system, LBPS02 was obtained (Fig. 1A and B). As detected via HPLC, the molecular weight of LBPS02 demonstrated to be $68 \mathrm{kDa}$. No absorbance peak was detected at the wavelength of 260 or $280 \mathrm{~nm}$ in the UV spectra indicating the lack of nuclear acid and protein contamination in LBPS02 (Fig. 1C). Furthermore, according to the FTIR spectra, hydroxyl $\left(3,450 \mathrm{~cm}^{-1}\right), \mathrm{C}-\mathrm{H}\left(2,940 \mathrm{~cm}^{-1}\right), \mathrm{C}=\mathrm{O}$ $\left(1,660 \mathrm{~cm}^{-1}\right), \mathrm{C}-\mathrm{O}-\mathrm{C}$ and C-O-H $\left(950-1,200 \mathrm{~cm}^{-1}\right)$ were present in LBPS02 (Fig. 1D). Periodate oxidation-Smith degradation is widely used to analyze the linkages of glucose in purified polysaccharides (Fig. 1E and F). The consumption of sodium periodate of LBPSO2 is presented in Fig. 1E. Following analysis of LBPS02 hydrolysates via HPLC, L-rhamnose monohydrate, glucose, glycerol and erythritol were detected (Fig. 1F).

LBPS02 protects DPC12 cells against L-Glu induced cell damage. LBPS02 alone exerted no effect on DPC12 cell viability; however, 3-h pretreatment with LBPS02 improved cell viability $19.1 \%$ in L-Glu-exposed DPC12 cells compared with those treated with L-Glu only ( $<<0.05$; Fig. 2A). LBPS02 at doses of 10 and $30 \mu \mathrm{g} / \mathrm{ml}$ reduced caspase- 3 activation by $\sim 24.6$ and $33.9 \%$, respectively, in L-Glu-induced cells 

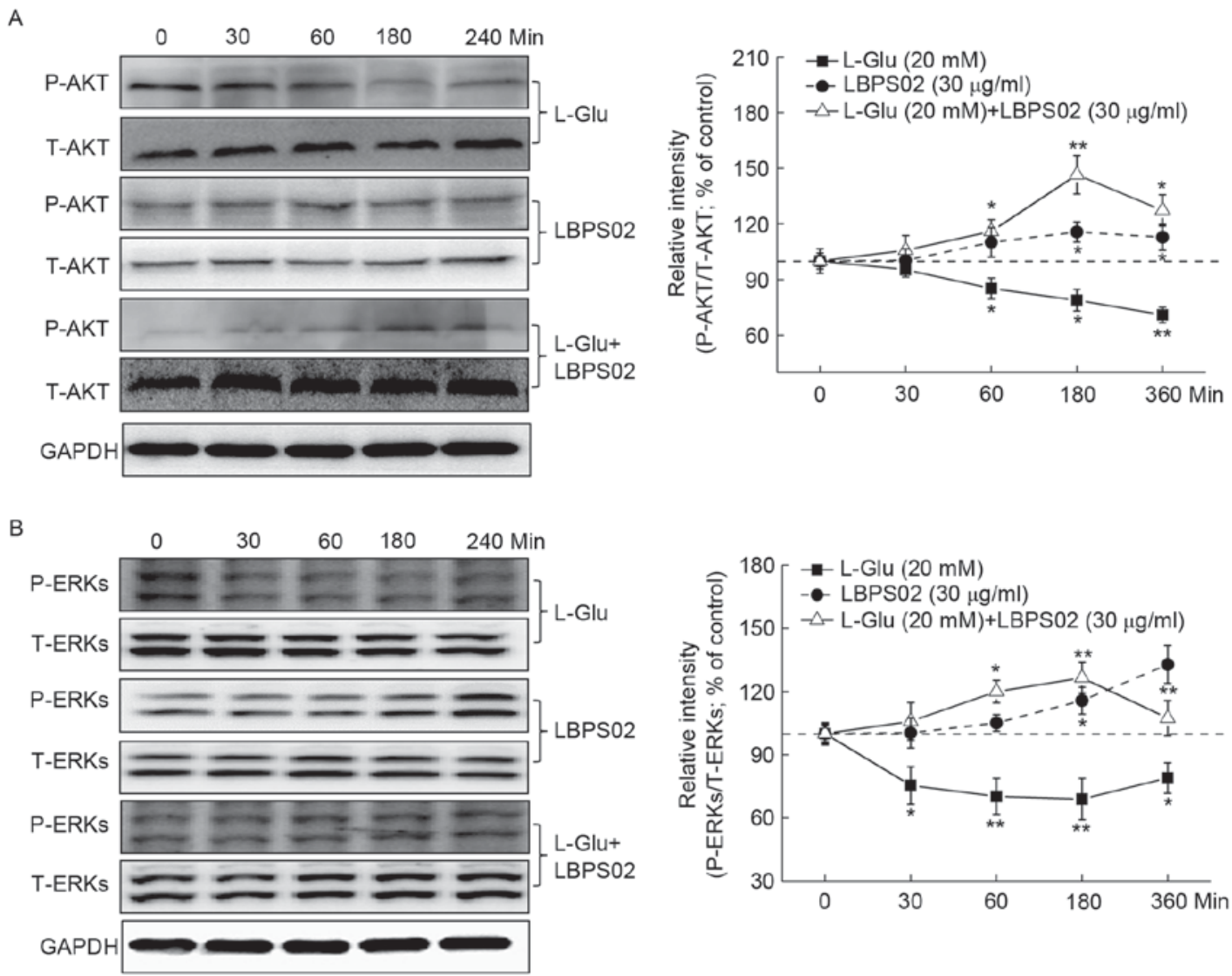

Figure 4. Akt and ERK signaling contributes to LBPS02-mediated neuroprotection against L-Glu-induced DPC12 cells damage. DPC12 cells were treated with $30 \mu \mathrm{g} / \mathrm{ml} \mathrm{LBPS02}$ or $20 \mathrm{mM} \mathrm{L}$-Glu alone and collected at 0,30, 60, 180 and $240 \mathrm{~min}$. For co-treatment, after 3-h $30 \mu \mathrm{g} / \mathrm{ml}$ of LBPS02 pre-treatment, cells were collected at 0,30,60, 180 and $240 \mathrm{~min}$ after exposing to $20 \mathrm{mM}$ of L-Glu. The levels of (A) p-Akt and t-Akt, and (B) p-ERK and t-ERK, were detected by western blot. Data are expressed as a percentage of corresponding 0 -min collected cells and the mean \pm standard deviation $(\mathrm{n}=3)$. ${ }^{*} \mathrm{P}<0.05$ and ${ }^{* * *} \mathrm{P}<0.01$ vs. 0-min collected cells. p-, phospho-; t-, total; Akt, protein kinase B; L-Glu, L-glutamine; LPBS, Lycium barbarum polysaccharide; ERK, extracellular signal-regulated kinase.

(P<0.05; Fig. 2B). LBPS02 strongly restored the apoptosis rate in L-Glu-exposed DPC12 cells $(\mathrm{P}<0.01$; Fig. 2C). An accumulation of intracellular ROS was observed following L-Glu treatment; LBPS02 strongly suppressed intracellular ROS levels induced by L-Glu, as measured by flow cytometry (Fig. 2D) and reagent color-developing method of a ROS detection kit $(\mathrm{P}<0.01$; Fig. 2E). Furthermore, the protective effect of LBPS02 against cytotoxicity was strongly enhanced by 30 min pretreatment with $1 \mathrm{mM} \mathrm{NAC}$, a ROS inhibitor (75.7 $\pm 2.5 \%$ vs. $88.7 \pm 3.7 \%$; P<0.05; Fig. 2 F).

LBPSO2 improved mitochondrial function. MMP is responsible for intrinsic and extrinsic apoptosis. As indicated by the enhanced red fluorescence intensity, LBPS02 restored depolarization of MMP in L-Glu-treated cells (Fig. 3A). Additionally, a significant reduction on $\mathrm{Bcl}-2$ expression, and enhancement of Bax and cleaved caspase 3 were observed in L-Glu-treated DPC12 cells $(\mathrm{P}<0.05$; Fig. 3B). LBPS02 pre-treatment at $30 \mu \mathrm{g} / \mathrm{ml}$ resulted in a $19.1 \%$ enhancement on Bcl-2 level, and 21.7 and $25.2 \%$ suppression on Bax and cleaved caspase-3 expressions, respectively, compared with cells treated with L-Glu only ( $\mathrm{P}<0.01$; Fig. 3B). LBPS02 also influenced the expressions of total caspase 3 (Fig. 3B).
Akt and ERKs contribut to the neuroprotective effect LBPSO2. L-Glu strongly suppressed the levels of p-Akt and p-ERKs especially from 60 to $240 \mathrm{~min}(\mathrm{P}<0.05$; Fig. 4), while LBPS02 alone enhanced the levels of p-Akt and p-ERKs in DPC12 cells $(\mathrm{P}<0.05$; Fig. 4). Compared with L-Glu-treated cells, LBPS02 pretreatment strongly reversed the reduced activation of Akt and ERKs caused by $20 \mathrm{mM} \mathrm{L-Glu} \mathrm{(P<0.05;} \mathrm{Fig.} \mathrm{4).}$

\section{Discussion}

The chemical structures of polysaccharides are responsible for their bioactivities. LBPS02, purified from L. barbarum, was systemically identified and characterized in the present study. No absorbance at wavelength of 260 and $280 \mathrm{~nm}$ was observed in UV spectrum confirming that the lack of nuclear acid and proteins within the LBPS02 extract. As revealed by the FTIR spectrum, the $\mathrm{C}-\mathrm{H}, \mathrm{C}=\mathrm{O}, \mathrm{C}-\mathrm{O}-\mathrm{C}$ and $\mathrm{C}-\mathrm{O}-\mathrm{H}$ structures were confirmed to be present in LBPS02. In periodate oxidation-Smith degradation analysis, $1 \rightarrow$ and/or $1 \rightarrow 6$ linkages may exist within LBPS02, indicated by the low production of formic acid. The presence of $1 \rightarrow 3$ linkages within LBPS02 is confirmed by the consumption of $<1 \mathrm{~mol}$ periodate. In permanganate oxidation, the observation of 
erythritol in hydrolysates indicates the presence of $1 \rightarrow 4$ linkages. Further information on the skeleton structure of LBPSO2 will be analyzed by combining the present results with the results of nuclear magnetic resonance.

The current study successfully confirmed the neuroprotective effects of LBPSO2 by observing its regulatory activities on cell viability, apoptosis rate, ROS accumulation, MMP and apoptosis-associated protein expressions in DPC12 cells. The data reveal that LBPS02-mediated neuroprotection may involve the mitochondria-associated apoptotic pathway.

Central nervous system stress may cause high levels of L-Glu, which leads to cell damage (18). L-Glu-induced cell apoptosis may be initiated by mitochondrial dysfunction. The accumulation of ROS is causes the opening of mitochondrial permeability transition pore, which further induces mitochondria apoptosis (19). There is a positive feedback loop between intracellular ROS and mitochondria (20). In the present study, NAC, a ROS inhibitor, significantly enhanced LBPS02-mediated neuroprotection, which confirmed the roles of ROS. Furthermore, LBPS02 suppressed the levels of cleaved caspase- 3 and Bax, and enhanced the expression of Bcl-2 in L-Glu-exposed cells. The ratio of Bcl-2 and Bax serves as an index of mitochondria-associated cell apoptosis (21). The caspase family has a central role in neurodegeneration, and activated caspase-3 may translocate into nucleus to regulate nuclear substrates associated with apoptosis (22). The disruption of MMP induces activation of the enzymatic apoptotic machinery of caspases, particularly caspase-3. The present data indicate that LBPS02 mediates neuroprotection against L-Glu-induced DPC12 cell damage via effects on caspase-dependent mitochondrial signaling.

ERKs and Akt are associated with cell proliferation and survival. The inhibition of ERKs phosphorylation leads to suppressed Bcl-2 and Bcl-xL expressions (23), which may influence mitochondrial function. It has been previously demonstrated that L-Glu strongly suppressed the levels of ERKs phosphorylation in DPC12 cells (5). Furthermore, the activation of Akt is reported to inhibit the expression of pro-apoptotic proteins, including Bcl-2 family proteins (24), which may further regulate mitochondrial function. Bone marrow mesenchymal stem cell-derived microvesicles protect PC12 cells against L-Glu-induced excitotoxicity by increasing Akt phosphorylation and Bcl-2 expression (25). The isomers albiflorin and paeoniflorin exhibit neuroprotective effects against L-Glu-induced toxicity in PC12 cells, with their effects associated with the modulation of $\mathrm{Akt}$ activities (26). Taking these results together, it is proposed that the neuroprotective effects of LBPS02 are at least partially associated with the restoration of Akt and ERKs, and the subsequent inhibition of the mitochondrial apoptotic pathway.

There are certain limitations in the present study. Initially, although the effects of LBPS02 on mitochondrial function, ROS accumulation, and the activation of Akt and ERKs were observed, the association among them requires further investigation. Additionally, based solely on the results of the present study, the relationship between the structure of LBPSO2 and its bioactivity is difficult to identify. All these limitations will be investigated in further studies investigating L. barbarum.
In conclusion, LBPS02 was successfully purified from $L$. barbarum, and exhibits protective effects against L-Glu-induced DPC12 cell apoptosis. Further experiments reveal that the mitochondria-associated pathway has a central role during this effect. Purified polysaccharides from $L$. barbarum may be a potential candidate for neurodegenerative disease therapy.

\section{Acknowledgements}

The present study is supported by Health and Family Planning Commission of Jiangsu Province in China (grant no. H201536), the Social Development Project of Zhenjiang Province in China (grant no. SH2014028), Research Fund for the Doctoral Program of Affiliated Hospital of Jiangsu University in China (grant no. jdfyRC-2015004) and Scientific Research Program of the Affiliated Hospital of Jiangsu University in China (NO. jdfyRC-2013003).

\section{References}

1. Hisahara S and Shimohama S: Toxin-induced and genetic animal models of Parkinson's disease. Parkinsons Dis 2011: 951709, 2010.

2. Schulz JB and Falkenburger BH: Neuronal pathology in Parkinson's disease. Cell Tissue Res 318: 135-147, 2004.

3. Reynolds IJ and Hastings TG: Glutamate induces the production of reactive oxygen species in cultured forebrain neurons following NMDA receptor activation. J Neurosci 15: 3318-3327, 1995.

4. Akaishi T, Nakazawa K, Sato K, Saito H, Ohno Y and Ito Y: Hydrogen peroxide modulates whole cell $\mathrm{Ca} 2+$ currents through L-type channels in cultured rat dentate granule cells. Neurosci Lett 356: 25-28, 2004.

5. Wang D, Guo TQ, Wang ZY, Lu JH, Liu DP, Meng QF, Xie J, Zhang XL, Liu Y and Teng LS: ERKs and mitochondria-related pathways are essential for glycyrrhizic acid-mediated neuroprotection against glutamate-induced toxicity in differentiated PC12 cells. Braz J Med Biol Res 47: 773-779, 2014.

6. Lee CS, Kim YJ, Lee MS, Han ES and Lee SJ: 18beta-Glycyrrhetinic acid induces apoptotic cell death in $\mathrm{SiHa}$ cells and exhibits a synergistic effect against antibiotic anti-cancer drug toxicity. Life Sci 83: 481-489, 2008.

7. Kim EH, Jang MH, Shin MC, Shin MS and Kim CJ: Protective effect of aqueous extract of Ginseng radix against 1-methyl-4-phenylpyridinium-induced apoptosis in PC12 cells. Biol Pharm Bull 26: 1668-1673, 2003.

8. Choi JG, Kim HG, Kim MC, Yang WM, Huh Y, Kim SY and Oh MS: Polygalae radix inhibits toxin-induced neuronal death in the Parkinson's disease models. J Ethnopharmacol 134: 414-421, 2011.

9. Hu S, Wang D, Zhang J, Du M, Cheng Y, Liu Y, Zhang N, Wang D and Wu Y: Mitochondria related pathway is essential for polysaccharides purified from sparassis crispa mediated neuro-protection against glutamate-induced toxicity in differentiated PC12 Cells. Int J Mol Sci 17: pii: E133, 2016.

10. Methacanon P, Madla S, Kirtikara K and Prasitsil M: Structural elucidation of bioactive fungi-derived polymers. Carbo Poly 60: 199-203, 2005.

11. Zareisedehizadeh S, Tan CH and Koh HL: A Review of Botanical Characteristics, Traditional Usage, Chemical Components, Pharmacological Activities, and Safety of Pereskia bleo (Kunth) DC. Evid Based Complement Alternat Med 2014: 326107, 2014.

12. Chen W, Cheng X, Chen J, Yi X, Nie D, Sun X, Qin J, Tian M, Jin $G$ and Zhang $X$ : Lycium barbarum polysaccharides prevent memory and neurogenesis impairments in scopolamine-treated rats. PLoS One 9: e88076, 2014.

13. Zhang XR, Zhou WX, Zhang YX, Qi CH, Yan H, Wang ZF and Wang B: Macrophages, rather than $\mathrm{T}$ and $\mathrm{B}$ cells are principal immunostimulatory target cells of Lycium barbarum L. polysaccharide LBPF4-OL. J Ethnopharmacol 136: 465-472, 2011. 
14. Gao K, Liu M, Cao J, Yao M, Lu Y, Li J, Zhu X, Yang Z and Wen A: Protective effects of Lycium barbarum polysaccharide on 6-OHDA-induced apoptosis in PC12 cells through the ROS-NO pathway. Molecules 20: 293-308, 2015.

15. Mi XS, Feng Q, Lo AC, Chang RC, Lin B, Chung SK and So KF: Protection of retinal ganglion cells and retinal vasculature by Lycium barbarum polysaccharides in a mouse model of acute ocular hypertension. PLoS One 7: e45469, 2012.

16. Song J, Wang Y, Liu C, Huang Y, He L, Cai X, Lu J, Liu Y and Wang D: Cordyceps militaris fruit body extract ameliorates membranous glomerulonephritis by attenuating oxidative stress and renal inflammation via the NF- $\mathrm{\kappa B}$ pathway. Food Funct 7 : 2006-2015, 2016.

17. Linker A, Evans LR and Impallomeni G: The structure of a polysaccharide from infectious strains of Burkholderia cepacia. Carbohyd Res 335: 45-54, 2001.

18. Das A, Belagodu A, Reiter RJ, Ray SK and Banik NL: Cytoprotective effects of melatonin on C6 astroglial cells exposed to glutamate excitotoxicity and oxidative stress. J Pineal Res 45: 117-124, 2008.

19. Christophe M and Nicolas S: Mitochondria: A target for neuroprotective interventions in cerebral ischemia-reperfusion. Curr Pharm Des 12: 739-757, 2006.

20. Degli Esposti M and McLennan H: Mitochondria and cells produce reactive oxygen species in virtual anaerobiosis: Relevance to ceramide-induced apoptosis. FEBS Lett 430: 338-342, 1998
21. Raisova M, Hossini AM, Eberle J, Riebeling C, Wieder T, Sturm I, Daniel PT, Orfanos CE and Geilen CC: The Bax/Bcl-2 ratio determines the susceptibility of human melanoma cells to CD95/Fas-mediated apoptosis. J Invest Dermatol 117: 333-340, 2001

22. Luo M, Lu Z, Sun H, Yuan K, Zhang Q, Meng S, Wang F, Guo H, Ju X, Liu Y, et al: Nuclear entry of active caspase-3 is facilitated by its $\mathrm{p} 3$-recognition-based specific cleavage activity. Cell Res 20: 211-222, 2010.

23. Boucher MJ, Morisset J, Vachon PH, Reed JC, Lainé J and Rivard N: MEK/ERK signaling pathway regulates the expression of Bcl-2, Bcl-X(L), and Mcl-1 and promotes survival of human pancreatic cancer cells. J Cell Biochem 79: 355-369, 2000.

24. Maurer U, Preiss F, Brauns-Schubert P, Schlicher L and Charvet C: GSK-3-at the crossroads of cell death and survival. J Cell Sci 127: 1369-1378, 2014.

25. Lin SS, Zhu B, Guo ZK, Huang GZ, Wang Z, Chen J, Wei XJ and Li Q: Bone marrow mesenchymal stem cell-derived microvesicles protect rat pheochromocytoma PC12 cells from glutamate-induced injury via a PI3K/Akt dependent pathway. Neurochem Res 39: 922-931, 2014

26. Wang D, Tan QR and Zhang ZJ: Neuroprotective effects of paeoniflorin, but not the isomer albiflorin, are associated with the suppression of intracellular calcium and calcium/calmodulin protein kinase II in PC12 cells. J Mol Neurosci 51: 581-590, 2013. 